\title{
SUPPLEMENTARY FOOD THERAPY FOR THE RECOVERY OF MALNOURISHED CHILDREN O-59 MONTHS: A SYSTEMATIC REVIEW
}

\author{
Solikhah Eli Setiyani, Fitria Siswi Utami
}

Universitas Aisyiyah Yogyakarta

\begin{abstract}
Background: Acute malnutrition is the highest cause of death among children under five. This is because children are a group that is vulnerable to health problems, one of which is infection. In this phase there is a very rapid growth and development in children. This problem occurs in part in low- and middle-income countries. This study aimed to review the effect of supplementary food therapy for recovery among malnourished children aged 0-59 months.

Subjects and Methods: This was a scoping review using the Arksey and O'Malley framework. The framework used to identify relevant studies is Population, Intervention, Comparison, and Outcome (PICO), with a search strategy using 5 databases, namely PubMed, Science Direct, Proquest, Wiley, and Google Scholar which match the inclusion and exclusion criteria.

Results: Supplementary food therapy for recovery of malnourished children 0-59 months could be done with inpatient and outpatient care using Modified Dried Skilled Milk and Coconut Oil (Modisco), Ready to use Therapeutic Food (RUTF), Soy Maize Sorghum RUTF (SMS RUTF), $\mathrm{F}$ 75, and F 100. The most widely used recovery supplementary food therapies are Modisco, RUTF, SMS RUTF, F75 and F100. RUTF in Indonesia has not been widely used for the therapy of malnourished children, while for $\mathrm{F} 75$ and F100 it has been used as a treatment but not maximally because it tastes bad so it is not liked by children.

Conclusion: Several studies have examined the effectiveness of these supplementary foods, apart from being used in the hospital, they can also be given on an outpatient basis with the supervision of related health workers.
\end{abstract}

Keywords: children, malnutrition, therapy, supplementary food

Correspondence:

Solikhah Eli Setiyani. Universitas Aisyiyah Yogyakarta, Indonesia. Email: elisetiyanio1@gmail.com 